\title{
Hot-Injection Thermolysis of Cobalt Antimony Nanoparticles with Co(II)-Oleate and Sb(III)-Oleate
}

\author{
Jong-Pil Ahn*, Min-Suk Kim****, Se-Hoon Kim*****, Byung-Ha Lee****, \\ Do-Kyung Kim*****, and Joo-Seok Park**t \\ *Department of Business Corperation Center, Korea Institute of Ceramic Engineering and Technology, Jinju 52851, Korea \\ ** School of Materials Engineering, Inha University, Incheon 22219, Korea \\ ***Department of Materials Science and Engineering, Myongji University, Yongin 17058, Korea \\ ****Department of Pharmacology, College of Medicine, Konyang University, Daejeon 35365, Korea \\ (Received March 14, 2016; Revised April 22, 2016; Accepted April 26, 2016)
}

\begin{abstract}
A novel strategy for the synthesis of $\mathrm{CoSb}_{2}$ nanoparticles is demonstrated via preparation of novel organometallic complexes. Hydrated cobalt oleate $(\mathrm{CoOl})$ and non-hydrated antimony oleate ( $\mathrm{SbOl}$ ) complexes are synthesized as precursors. $\mathrm{The}^{\mathrm{CoSb}} \mathrm{b}_{2}$ nanoparticles are prepared by hot injection, which involves thermolysis of $\mathrm{CoOl}$ and $\mathrm{SbOl}$ in a non-coordinating solvent at $320{ }^{\circ} \mathrm{C}$. The coordination modes and distinct thermal behaviors of the intermediate non-hydrated SbOl complexes are comparatively investigated by thermo-analytical techniques. When the reaction temperature is increased, the particle size is found to increase linearly. The crystallinity of the $\mathrm{CoSb}_{2}$ nanoparticles prepared at $250^{\circ} \mathrm{C}$ is amorphous phase without any peaks. CoSb $b_{2}$ structural peaks start to appear at $300^{\circ} \mathrm{C}$ and dominant peaks with high crystallinity are synthesized at $320^{\circ} \mathrm{C}$. The potential chemical structures of non-hydrated $\mathrm{SbOl}$ and their reaction mechanisms by thermolysis are elucidated. The elemental composition and crystallographic structure of $\mathrm{CoSb}_{2}$ nanoparticles suggest a bimodal interaction of the organic shell and the nanoparticle surface, with a chemical absorbed inner layer and physically absorbed outer layer of carboxylic acid.
\end{abstract}

Key words : Solution process, Coordinate, $\mathrm{CoSb}_{2}$ nanoparticles, Thermolysis, Hot-injection

\section{Introduction}

$\mathrm{D}$ ue to their high energy density and long cycle life, Li-ion batteries are used to power portable electronic devices, ranging from small-scale electronic devices to electric vehicles. On the one hand, there is a substantial interest in increasing the energy density of Li-ion batteries; on the other hand, there is a growing need for battery flexibility and shape adaptation in order to meet consumer needs and demands. ${ }^{1,2)}$ Among all battery technologies, Li-ion batteries exceed any rival technology by at least a factor 2.5 in terms of energy density. ${ }^{3)}$ However, the use of Li-ion batteries in emerging PHEVs (plug-in hybrid electric vehicles), HEVs (hybrid electric vehicles) and EVs (electric vehicles) requires further improvements in such areas as energy density, cycle life, environmental compatibility and safety. To resolve these problems, large efforts have been made to develop innovative electrode materials with specifically engineered nanostructures. ${ }^{4}$ Especially, nanocrystalline alloys are interesting candidates as anode materials in lithium-ion batteries because, due to their smaller particle size and

${ }^{\dagger}$ Corresponding author: Joo-Seok Park

E-mail : pjuju@kicet.re.kr

Tel : +82-55-792-2775 Fax : +82-55-792-2796 larger specific surface area, these alloys have more attractive properties than those of microsized alloy particles. The use of nanosized particles could improve the kinetics of Liions diffusion and result in an improvement of the electrochemical performances of electrodes. ${ }^{5)}$ Nanocrystalline $\mathrm{CoSb}_{2}$ nanoparticles could be used as a potential anode material in lithium-ion batteries. It was reported that electrodes fabricated with $\mathrm{CoSb}_{2}$ nanoparticles exhibited large reversible capacity with good cycling behavior. Nanosized alloy particles with excellent electrochemical performance are a strong candidate as a promising anode material in lithium-ion batteries. ${ }^{6}$ )

The synthesis of metal oxides and metal nanoparticles by the thermolysis of a metal oleate (MeOl) complex has received significant attention compared to conventional methods such as hydrothermal and oil phase syntheses. ${ }^{7}$ Hyeon et al. report on the nucleation kinetics of iron oxide nanocrystals during thermolysis of the FeOl complex in a high boiling point solvent. ${ }^{8}$ Also, cobalt ferrite nanoparticles with a narrow size distribution have been synthesized by thermolysis of the Fe-CoOl complex. The influence of aging time during the decomposition of the $\mathrm{Fe}-\mathrm{CoOl}$ complex has been studied in terms of the structure, chemical composition, size, and magnetic relaxation of cobalt ferrite nanoparticles. ${ }^{9)}$ Uniform sphere-like Co-doped iron oxide nanoparticles have also been studied in the thermolysis of $\mathrm{FeOl}$ and $\mathrm{CoOl}$ 
in the presence of oleic acid (OA). The particle size of codoped iron oxide can be changed by variation of the $\mathrm{Co} / \mathrm{Fe}$ mole ratio. ${ }^{10)}$ In this work, nearly monodisperse, strongly crystalline, superparamagnetic $\mathrm{CoFe}_{2} \mathrm{O}_{4}$ nanoparticles with diameters of $6 \mathrm{~nm}$ can be synthesized in an OA-water-pentanol system. Another approach, i.e. hydrothermal synthesis, is used as an efficient and eco-friendly alternative method. The particles are synthesized by changing the reaction conditions such as the hydrolysis of $\mathrm{MeOl}$ in organic phase. Particle size of 5-8 $\mathrm{nm}$ diameter can be tuned by polarity-driven precipitation into the water phase. ${ }^{11)}$ It is also possible to prepare $\mathrm{CoO}$ nanocrystals (CoO NCs) by thermolysis of $\mathrm{CoOl}$ complex. Fatty acid coated nanoparticles are transferred to the water phase via facile phasetransfer method with amphiphilic surfactants such as anionic (sodium dodecyl sulfate, SDS), neutral (Pluronic F127, PF127) and cationic (cetyltrimethyl ammonium bromide, CTAB) surfactants. ${ }^{12)}$ Clavel et al. ${ }^{13)}$ report cobalt and manganese doped $\mathrm{ZnO}$ achieved using the solvothermal method, which involves the reaction of zinc and cobalt acetate or $\mathrm{MnOl}$ in benzyl alcohol and which leads to pure inorganic nanoparticles. The addition of an inert solvent, which is used to control the amount of benzyl alcohol, drastically influences the particle morphologies, which strongly influence the magnetic behavior.

The size and shape of the cobalt particles can be controlled by the interface between the particles and the adsorbed species. ${ }^{14)}$ Polymeric matrixes are used as stabilizing agents to restrict the nucleation; these matrixes are replaced by metal coordinating agents such as OA. ${ }^{15)}$ Remarkably, metastable $\varepsilon$-cobalt phase can be prepared in the presence of TOPO or TPP, resulting in a crystal symmetry like that in $\beta$-manganese. ${ }^{16)}$ Schällibaum et al. ${ }^{15}$ report $\varepsilon$-cobalt nanoparticles with an average diameter of $4.5 \mathrm{~nm}$ fabricated by controlling the experimental conditions with larger quantities; process was based on thermal decomposition of dicobaltoctacarbonyl in the presence of OA and trioctylphosphine oxide (TOPO).

Xie et al. ${ }^{17,18)}$ report nanocrystalline $\mathrm{CoSb}_{2}$ obtained using solvothermal method at various temperatures. However, a sample prepared at $190^{\circ} \mathrm{C}$ retained unreacted Sb. Amornpitoksuk et al. ${ }^{19)}$ reported nanocrystalline $\mathrm{CoSb}_{2}$ formed by mechanical alloying with elemental Co and Sb powder. An arsenopyrite structure of $\mathrm{CoSb}_{2}$ starts to appear after $30 \mathrm{~h}$ of mechanical milling, with low crystallinity. Compared to these results, the thermolysis of hydrated $\mathrm{CoOl}$ and nonhydrated $\mathrm{SbOl}$ in non-coordinating solvent at $320^{\circ} \mathrm{C}$ shows high crystallinity of $\mathrm{CoSb}_{2}$ without any impurity phases.
In this work, we use a novel method to prepare organometallic precursors for thermal decomposition. When Sb is contact with water/moisture, it undergoes hydrolysis, forming antimony oxychloride and releasing hydrogen chloride, thus it is impossible to use $\mathrm{Sb}$ to prepare $\mathrm{SbOl}$ via conventional ion exchange with $\mathrm{NaOl}$. To avoid hydrolysis, antimony trichloride is used to directly coordinate equimolar of metal ions with OA, resulting in non-hydrated SbOl. In contrast, $\mathrm{CoOl}$ prepared by direct coordination of metal ions with carboxylic acid shows very poor yield and synthetic properties. Consequently, $\mathrm{CoOl}$ is prepared by ion exchange with $\mathrm{NaOl}$, resulting in hydrated $\mathrm{CoOl}$. Eventually, the hot-injection method is used to overcome the different decomposition temperatures of the non-hydrated $\mathrm{SbOl}$ and hydrated $\mathrm{CoOl}$. The particle sizes of $\mathrm{CoSb}_{2}$ synthesized by thermolysis of metal oleate can be tuned by changing the reaction time and temperature.

\section{Experimental Procedure}

Cobalt (II) chloride hexahydrate $\left(\mathrm{CoCl}_{2} \cdot 6 \mathrm{H}_{2} \mathrm{O}\right)$, antimony chloride $\left(\mathrm{SbCl}_{3}\right)$, oleic acid (OA, 90.0\%), hexane (99.0\%), ethanol (95\%) and 1-octadecene (ODE, 90.0\%) were obtained from Sigma-Aldrich. Sodium oleate $\left(\mathrm{NaOl}, \mathrm{CH}_{3}\left(\mathrm{CH}_{2}\right)_{7} \mathrm{CH}=\right.$ $\left.\mathrm{CH}\left(\mathrm{CH}_{2}\right)_{7} \mathrm{COONa}\right)$ was supplied by Junsei Chemical. All the chemicals except ODE were used without further purification. Volatile substances such as absorbed water and organic impurities with a low $\mathrm{Mw}$ in ODE were evaporated by heating at $200^{\circ} \mathrm{C}$ for $3 \mathrm{~h}$ prior to use. Double distilled and deionized water was used throughout. Hydrated $\mathrm{CoOl}$ complexes were produced by Hyeon's method ${ }^{8)}$ by directly reacting cobalt(II) chloride and $\mathrm{NaOl}$. Briefly, $4.758 \mathrm{~g}$ of $\mathrm{CoCl}_{2} \cdot 6 \mathrm{H}_{2} \mathrm{O}$ and $12.178 \mathrm{~g}$ of $\mathrm{NaOl}$ were dissolved in a mixture solvent composed of $80 \mathrm{~mL} \mathrm{EtOH}, 60 \mathrm{~mL}$ distilled water and $140 \mathrm{~mL}$ hexane in a closed bottle. The resulting solution was heated to $70^{\circ} \mathrm{C}$ and kept at that temperature for $4 \mathrm{~h}$. When the reaction was complete, the upper organic layer containing the $\mathrm{CoOl}$ complex was washed three times with $30 \mathrm{~mL}$ distilled water in a separatory funnel. After washing, hexane was evaporated off, resulting in the $\mathrm{CoOl}$ complex being in a waxy solid form. SbOl was prepared using the previously reported method ${ }^{10)}$ by directly coordinating the antimony chloride and OA (Table 1) in a threeneck round-bottom flask. The mixture was heated to $120^{\circ} \mathrm{C}$ to remove the physically absorbed water and the by-product, $\mathrm{HNO}_{3}$. During the reaction, the mixture color changed to brownish from transparent. The temperature of the reactants was decreased to room temperature and reactants

Table 1. Sample Notation and Composition of $\mathrm{CoOl}$ and $\mathrm{SbOl}$

\begin{tabular}{cccc}
\hline Sample notation & Metal source $(\mathrm{C}, \mathrm{A})$ & Surfactant $(\mathrm{S}, \mathrm{O})$ & Solvent $(\mathrm{M}, \mathrm{N})$ \\
\hline CoOl-CSM & $\mathrm{CoCl}_{2} \cdot 6 \mathrm{H}_{2} \mathrm{O}$ & Na Oleate & Mixture of hexane, EtOH and water \\
SbOl-AONx $(\mathrm{x}=2,3,4)$ & $\mathrm{SbCl}_{3}$ & Oleic acid & None \\
\hline
\end{tabular}

In sample notation, "C" means cobalt chloride, "A" means antimony chloride, "S" means sodium oleate, "O" means oleic acid, "M" means mixture of solvents, " $\mathrm{N}$ " means direct reaction without solvent 
were collected for analysis. The sample notation and preparation methods are described in Table 1. For example, $2 \mathrm{mmol}(1.244 \mathrm{~g}) \mathrm{CoOl}$ was dissolved in $35 \mathrm{~mL}$ of ODE in the three-neck round-bottom flask, degassed in a vacuum, purged three times with argon, and heated to 250, 300 and $320^{\circ} \mathrm{C}$. The holding time was varied from 10 to $60 \mathrm{~min}$. At these temperature, the solution of $\mathrm{SbOl}$ in $5 \mathrm{~mL}$ of ODE was quickly injected into the reaction vessel under magnetic stirring and the color of the solution changed immediately from light blue to dark black, indicating that the nucleation and subsequent growth of $\mathrm{CoSb}_{2}$ Nanoparticles had occurred. After the desired holding time, the mixture was cooled to room temperature. The lipid-coated $\mathrm{CoSb}_{2}$ Scheme 1 was dissolved in $5 \mathrm{~mL}$ hexane, precipitated by $10 \mathrm{~mL}$ ethanol and centrifuged at 14,000 rpm for $10 \mathrm{~min}$; next, the supernatant was carefully decanted. The washing process was repeated 5 times and the lipophilic $\mathrm{CoSb}_{2}$ nanoparticles were re-dispersed in $5 \mathrm{~mL}$ hexane, forming a stable suspension that was kept at $40^{\circ} \mathrm{C}$ for further use for characterization and application. Fourier transform infrared (FTIR) spectra were recorded at $20^{\circ} \mathrm{C}$ using ALPHA FT-IR spectrometers equipped with Platinum ATR (single reflection diamond ATR) from Bruker optics. The spectra were measured with a resolution of $1 \mathrm{~cm}^{-1}$; the wavenumber range was $800-1,800 \mathrm{~cm}^{-1}$. The samples were measured by dropping the samples on the surface of a facet of diamond ATR without any specific preparation of the specimens. Thermal gravimetric analysis (TGA), and differential thermal analysis (DTA) were carried out using a DTG-60H simultaneous DTA-TGA system from Micromeritics; differential scanning calorimetry (DSC) was performed using a DSC 50 from Shimadzu. In the data plots, the weight loss is expressed as a percentage of the initial sample weight and is plotted vs. temperature. DSC and DTA with nitrogen purge gas (20 $\mathrm{mL} / \mathrm{min})$ were used to heat samples $(5-10 \mathrm{mg})$ in platinum pans with pierced lids (Micromeritics). Samples were measured from 20 to $400^{\circ} \mathrm{C}$ at a nominal heating rate of $10^{\circ} \mathrm{C} /$ min. X-Ray Diffraction (XRD) was measured using a D/max 2200V/PC from Rigaku. Samples were measured from 10 to $80^{\circ}$ with a scan speed of $5 \% \mathrm{~min}$. X-ray Photoelectron Spectroscopy (XPS) was performed using a PHI 5000 VersaProbe $^{\mathrm{TM}}$ from Ulvac. Particle size was calculated using FWHM (Full Width at Half Max) and Scherrer's formula, ${ }^{20)}$

$$
t=(K \times \lambda) /(B \times \cos \theta B)
$$

( $t=$ thickness of crystallite, $K=$ constant dependent on crystallite shape (0.89), $\lambda=$ x-ray wavelength, $B=$ FWHM or integral breadth, $\theta B=$ Bragg angle).

\section{Results and Discussion}

In our synthesis strategy, $\mathrm{CoSb}_{2}$ nanoparticles are synthesized by "hot-injection" method in which non-hydrated SbOl dissolved in ODE is directly injected into a hot solution of hydrated $\mathrm{CoOl}$ in ODE at a given temperature. In a binary reaction system, two metallic oleates are involved in the reaction. Thus, the physiochemical properties of the metal oleate related to the two elements should be considered in order to nucleate the $\mathrm{CoSb}_{2}$ nanoparticles. Especially, because the reaction activities of the hydrated $\mathrm{CoOl}$ and the non-hydrated SbOl precursors differ from each other, a separated nucleus will be generated and grow into a heterogeneous structure. A hydrated $\mathrm{CoOl}$ complex was advantageously prepared ${ }^{8)}$ by coordination of divalent inorganic salts and carboxylic acid $(\mathrm{RCOOH})$ with various molar ratios at $120^{\circ} \mathrm{C}$. The divalent metal ion can be introduced in any of a variety of forms, but in particular a divalent inorganic metal salt is introduced. These multivalent transition metal cations and particularly $\mathrm{Co}$ (II) are essentially capable of coordination of $\mathrm{RCOOH}$, including those that have 10 to 22 carbon atoms. Due to their strong metal cation chelating ability, carboxyl acid groups in monobasic carboxylic acid are ionized by neutralization with metal ions. Typical reaction equations for hydrated $\mathrm{CoOl}$ and non-hydrate $\mathrm{SbOl}$ complexes are described as follows:

$$
\begin{aligned}
& \mathrm{CaCl}_{2} \cdot 6 \mathrm{H}_{2} \mathrm{O}+2 \mathrm{CH}_{3}\left(\mathrm{CH}_{2}\right)_{7} \mathrm{CH}=\mathrm{CH}\left(\mathrm{CH}_{2}\right)_{7} \mathrm{COONa} \\
& \rightarrow \mathrm{Co}\left(\mathrm{C}_{17} \mathrm{H}_{33} \mathrm{COO}\right)_{2}+2 \mathrm{NaCl} \\
& \mathrm{SbCl} l_{3}+3 \mathrm{CH}_{3}\left(\mathrm{CH}_{2}\right)_{7} \mathrm{CH}=\mathrm{CH}\left(\mathrm{CH}_{2}\right)_{7} \mathrm{COOH} \\
& \rightarrow \mathrm{Sb}\left(\mathrm{C}_{17} \mathrm{H}_{33} \mathrm{COO}\right)_{3}+3 \mathrm{HNO}_{3} \uparrow
\end{aligned}
$$

Non-hydrated $\mathrm{CoOl}$ as an organometallic precursor is less suitable than hydrated $\mathrm{CoOl}$ for the synthesis of $\mathrm{CoSb}_{2}$ by thermolysis. The particle sizes of $\mathrm{CoSb}_{2}$ are tuned using equimolar ratios of metal ions and carboxylic acid, without excessive passivating surfactant/solvent. Especially, the molecular structures of non-hydrated $\mathrm{SbOl}$ complexes are strongly correlated to the molar ratio of $\mathrm{Sb} / \mathrm{OA}$, and the correlation of coordination modes; the thermal behavior of nonhydrated $\mathrm{SbOl}$ and their particle formation are investigated.

The molecular structures and thermal behaviors of nonhydrated $\mathrm{SbOl}$ and hydrated $\mathrm{CoOl}$ complexes were determined by FTIR, DSC, TGA and DTA. The solid waxy forms of non-hydrated $\mathrm{SbOl}$ and hydrated $\mathrm{CoOl}$ complexes were subjected to thermal analysis to study the reaction mechanism of nanoparticle formation. Based on FTIR data, nonhydrated $\mathrm{SbOl}$ samples can be seen to be a mixture of OA and $\mathrm{SbOl}$ with different coordination modes. Fig. 1(a) shows DTA curves of hydrated $\mathrm{CoOl}$ prepared by ion exchange with $\mathrm{NaOl}$ and non-hydrate $\mathrm{SbOl}$ prepared with a different molar ratio of antimony ion and OA. The first transition peak that appeared at $73^{\circ} \mathrm{C}$ for hydrated CoOl-CSM is due to the removal of $\mathrm{EtOH}$, which was used as an immiscible solvent between the aqueous and oil phases for ion exchange of $\mathrm{Na}^{+}$to $\mathrm{Co}^{2+}$. According to Bronstein, the second transition appears at $131^{\circ} \mathrm{C}$ for the crude hydrated CoOlCSM sample due to the removal of chemically absorbed water, ${ }^{21)}$ whereas no such endothermic peak appeared for non-hydrated SbOl. The absence of this endothermic peak is supplementary evidence supporting the prediction of the 


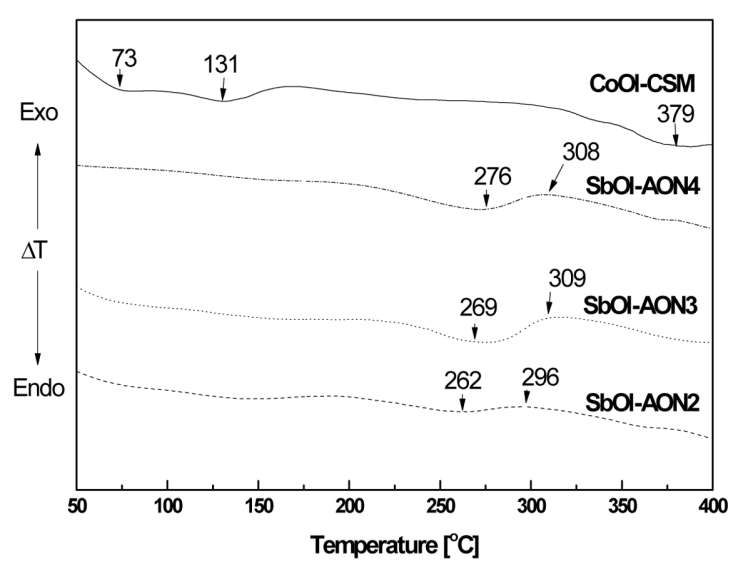

(a)

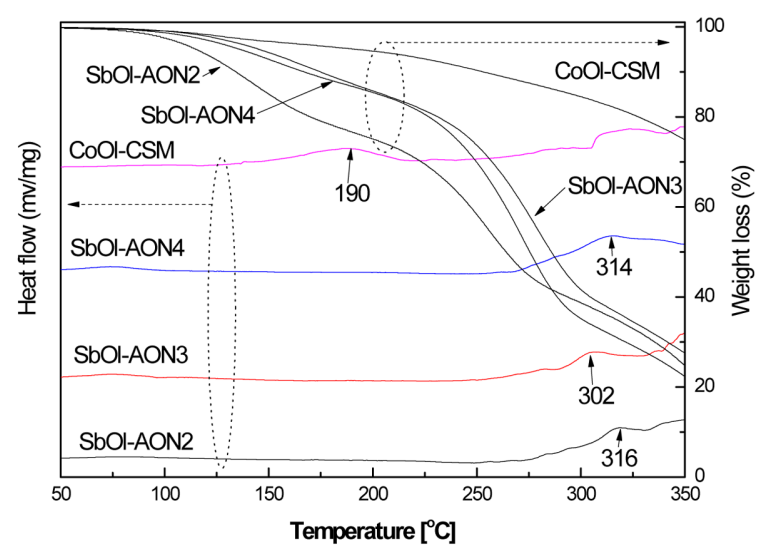

(b)

Fig. 1. (a) DTA curves and (b) TGA and DSC curves of hydrated $\mathrm{CoOl}$ prepared by exchanging the cobalt ion with $\mathrm{NaOl}$ and non-hydrate $\mathrm{SbOl}$ prepared with different molar ratio of antimony ion and oleic acid. (SbOl-AON2 SbOl-AON4 and CoOl-CSM).

FTIR as can be seen in Fig. 1(a), the first endothermic peak of the non-hydrated SbOl complexes appeared at 262 $276^{\circ} \mathrm{C}$ in all samples; this peak is assigned to the start of the dissociation of the oleate ligand. With an increasing ratio of OA against antimony ions, the endothermic peak was right shifted, indicating a stronger association of oleate ligand and antimony ion. The TGA curves show good agreement with the endothermic peak in Fig. 1(b). In non-hydrated SbOl-AON4 complexes, for example, the on-set temperature of the first weight loss is determined to be $215^{\circ} \mathrm{C}$ the weight loss from $215^{\circ} \mathrm{C}$ to $304^{\circ} \mathrm{C}$ is $49 \%$.

The first transition appears at around $302-316^{\circ} \mathrm{C}$ in the DSC curves of the $\mathrm{SbOl}$ samples as a shallow exothermic peak. According to Bronstein and Hyeon ${ }^{8,21)}$ the peak near $300^{\circ} \mathrm{C}$ can be assigned to dissociation of the remaining oleate ligands from the hydrated metal oleate precursors that led to particle growth. Interestingly, the thermal decomposition temperature of $\mathrm{OA}$ was determined to be $266^{\circ} \mathrm{C}$ so, obviously, coordination with the metal ion had stabilized the oleate molecules and increased the decomposition/dissociation temperature of $\mathrm{OA}$. In the non-hydrated

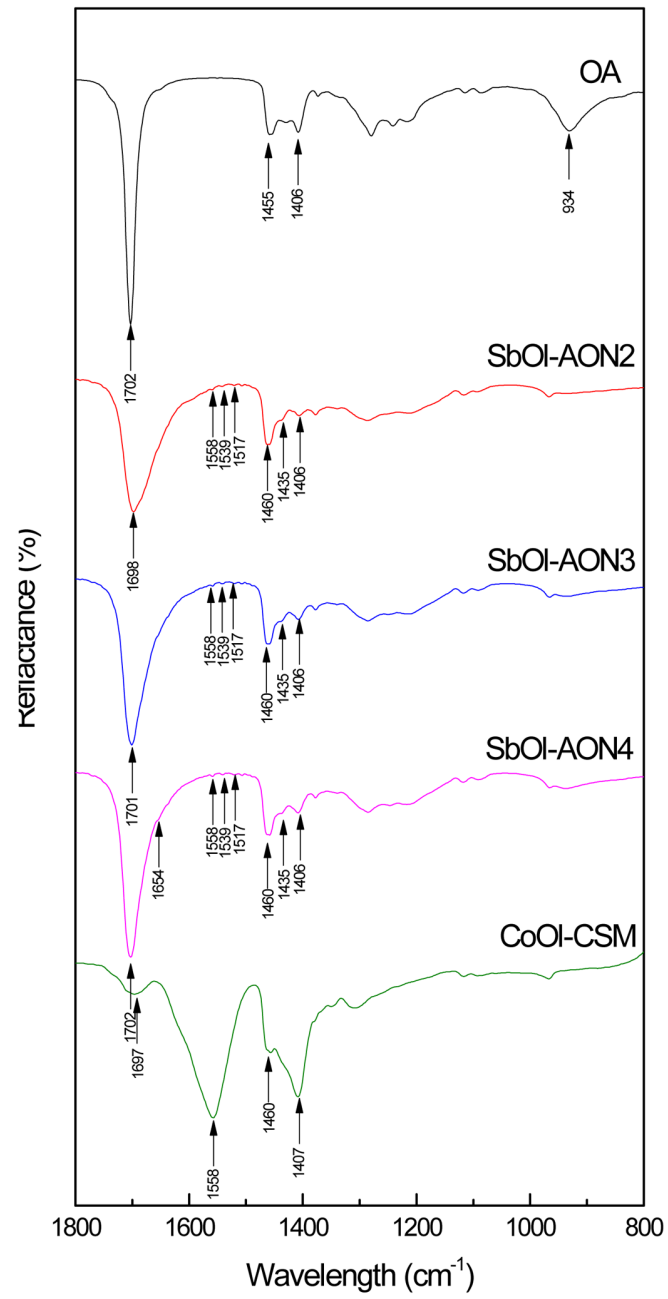

Fig. 2. FTIR spectra of oleic acid, hydrated $\mathrm{CoOl}$ prepared by exchanging the cobalt ion with $\mathrm{NaOl}$ and nonhydrate $\mathrm{SbOl}$ prepared with different molar ratio of antimony ion and oleic acid. (SbOl-AON2 SbOlAON4 and CoOl-CSM).

$\mathrm{SbOl}$ complexes, the amount of OA is increased from SbOlAON2 to SbOl-AON4, which matches the fact that the endothermic transition peaks increased from $262^{\circ} \mathrm{C}$ to $276^{\circ} \mathrm{C}$. The exothermic transition peaks match the second step weight loss from $296^{\circ} \mathrm{C}$ to $308^{\circ} \mathrm{C}$, as can be seen in the TGA curve of SbOl-AON4 in Fig. 1(b). The weight loss of the second step is $39 \%$, and thus it is reasonable to conclude that the first weight loss is due to the removal of free OA and the dissociation of one oleate ligand; the second weight loss from $276^{\circ} \mathrm{C}$ to $348^{\circ} \mathrm{C}$ is due to the dissociation of the remaining two oleate ligands. The significant separation of the transition peak of CoOl-CSM at $190^{\circ} \mathrm{C}$ is a clear indication of the complete separation of the nucleation and particle growth phases.

The structural influences of different amounts of OA are investigated for the formation of non-hydrated SbOl complexes and hydrated CoOl. Fig. 2 shows FTIR spectra of nonhydrated $\mathrm{SbOl}$ complexes prepared by varying the molar ratio 

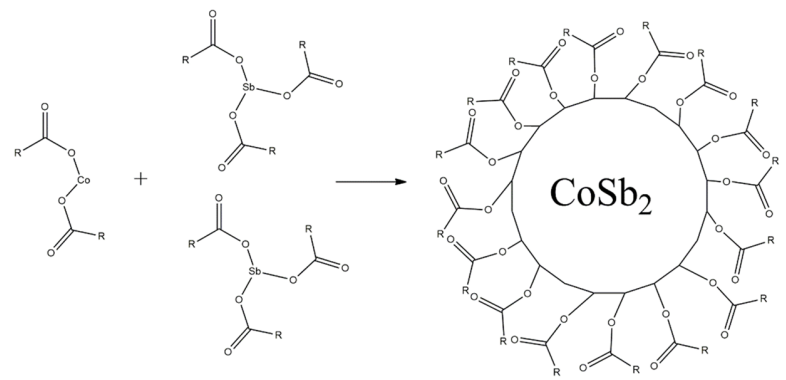

Scheme 1. Illustration of the $\mathrm{CoSb}_{2}$ nanoparticles prepared by thermal decomposition of hydrated $\mathrm{CoOl}$ and non-hydrated SbOlcomplexs.

of $\mathrm{SbCl}_{3}$ to $\mathrm{OA}$ from $1 / 2$ to $1 / 4$. Compared to pure OA, several new peaks appear in the region of $1,650-1,500 \mathrm{~cm}^{-1}$ in all non-hydrated $\mathrm{SbOl}$ samples due to newly formed antimony carboxylate; also, a peak appearing at $1,435 \mathrm{~cm}^{-1}$ is also assigned to carboxylate vibration. $1,558,1,539$ and $1,517 \mathrm{~cm}^{-1}$ are assigned to the $\mathrm{v}_{\mathrm{a}}(\mathrm{COO})$ of the non-hydrated $\mathrm{SbOl}$ complexes, among which the band at $1,558 \mathrm{~cm}^{-1}$ has the strongest intensity. A very small peak at $1,654 \mathrm{~cm}^{-1}$ appeared in the SbOl-AON4, and can be assigned to $\mathrm{C}=\mathrm{C}$ stretching mode, indicating that the double bond structure is intact in non-hydrated SbOl complexes. However, in SbOl-AON2 and SbOl-AON3, this peak was too weak to detect. The intensity of the characteristic unreacted OA band at $1,698 \mathrm{~cm}^{-1}$ increased with the decreasing ratio of $\mathrm{SbCl}_{3}$ and $\mathrm{OA}$, with SbOl-AON4 displaying the strongest intensity of $1,702 \mathrm{~cm}^{-1}$ band, which could be explained by the increasing amount of solid dimerized unreacted OA. The distinguished peaks appeared at $1,435 \mathrm{~cm}^{-1}$, and can be assigned to asymmetrical carboxylate vibration, indicating that bridging mode exists in these $\mathrm{SbOl}$ complexes. With increased OA concentration in the $\mathrm{SbOl}$ complex preparation, additional asymmetrical carboxylate vibration bands appeared at $1,517 \mathrm{~cm}^{-1}$, resulting in a new $\Delta=81 \mathrm{~cm}^{-1}$ therefore, in the carboxylate the head binds to the antimony atom in both bidentate and bridging modes. In Bronstein's work, in the region of 1,600 $1,500 \mathrm{~cm}^{-1}$, several new peaks were identified as metal carboxylate bands; three bands at 1,558, 1,539 and $1,517 \mathrm{~cm}^{-1}$ were assigned to asymmetrical carboxylate vibration, whereas the strong band appearing at $1,435 \mathrm{~cm}^{-1}$ was assigned to symmetrical vibration. In Fig. 4, a major peak can be seen to have appeared at $1,702 \mathrm{~cm}^{-1}$; this peak can be assigned to the $\mathrm{C}=\mathrm{O}$ stretching band of $\mathrm{OA}$ or to asymmetrical vibration of unidentate mode. ${ }^{22)}$ The intensities of the bands between 1,698 and 1,702 $\mathrm{cm}^{-1}$ increase linearly and shift wavenumber with the amount of OA increase. The coordination modes of the $\mathrm{SbOl}$ complexes were determined based on the position and separation of the asymmetrical and symmetrical antimony carboxylate peaks, and the splitting amount, $\Delta$. Four types of metal carboxylate coordination modes are described in Scheme 2 ionic, unidentate, bidentate and bridging mode. For $\Delta>200 \mathrm{~cm}^{-1}$, the unidentate mode can be expected; for $110 \mathrm{~cm}^{-1}<\Delta<200 \mathrm{~cm}^{-1}$, it is

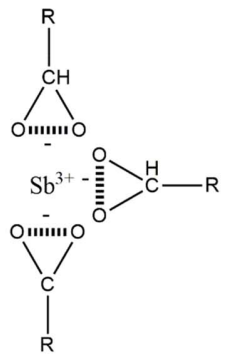

ionic

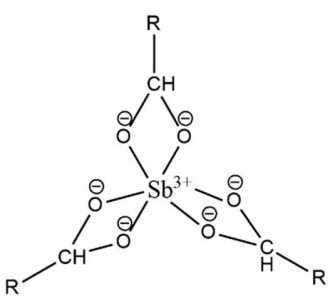

bidentate unidentate

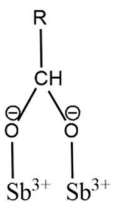

bridging *

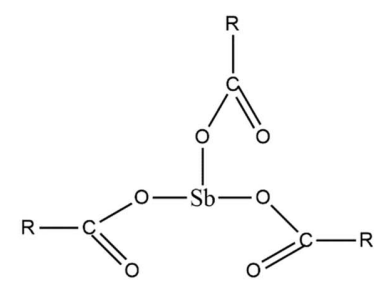

* The other two valent is not shown in the scheme for simplicity

Scheme 2. Four coordination modes of antimony carboxylate: ionic, unidentate, bidentate and bridging.

the bridging mode; and for $\Delta<110 \mathrm{~cm}^{-1}$, it is the bidentate mode. The difference between characteristic bands within the $\mathrm{v}(\mathrm{COO}-)$ region is $81 \mathrm{~cm}^{-1}$, revealing the bidentate mode. In the case of $\mathrm{CoOl}$, asymmetrical carboxylate vibration peaks at 1,406 and $1,558 \mathrm{~cm}^{-1}$ increased dramatically.

Figure 3 shows SEM images of the Co-Sb nanoparticles prepared by thermolysis of SbOl-AON3 and CoOl-CSM. a) the temperature of CoOl-CSM in ODE was found to increase to $320^{\circ} \mathrm{C}$ and SbOl-AON3 was hot-injected into ODE while holding the temperature for $10 \mathrm{~min} \mathrm{~b}$ ) the temperature of SbOl-AON3 and CoOl-CSM in ODE was increased to $320^{\circ} \mathrm{C}$ while holding the temperature for 10 min. The hot injection method shows a size dispersion of the

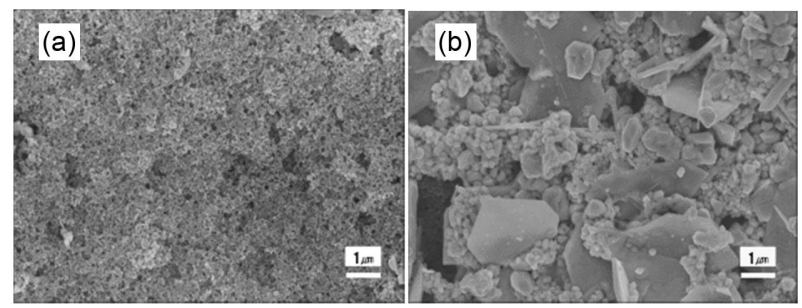

Fig. 3. SEM images of $\mathrm{CoSb}_{2}$ nanoparticles prepared by thermolysis of SbOl-AON3 and CoOl-CSM. a) the temperature of CoOl-CSM in ODE was increased to $320^{\circ} \mathrm{C}$ and $\mathrm{SbOl}-\mathrm{AON} 3$ was hot-injected into ODE while holding the temperature for $10 \mathrm{~min}$, and b) the temperature of SbOl-AON3 and CoOl-CSM in ODE was found to increase to $320^{\circ} \mathrm{C}$ and holding for $10 \mathrm{~min}$. 
Co-Sb nanocrystals that is remarkably small later adaptations have led to even smaller size dispersions than those that can be obtained using the conventional nucleation method. Nucleation and further crystal growth occur in different time stages. Especially, when mixtures of two organometallic compounds have different decomposition times and temperatures, nucleation is initiated from the substances with low decomposition temperature; further growth of another substance on the surface of the nuclei is formed as a separated phase. From Fig. 3(b), which shows a clear difference of the shapes, it can be seen that there are at least two different crystal structures. Antimony is quite volatile and starts to nucleate at a lower temperature than cobalt does. In contrast, it is difficult to nucleate cobalt at a lower temperature. Therefore, antimony particles were used as nuclei of the $\mathrm{CoSb}_{2}$ particles and can be seen as plate-like shapes with a size of several micrometers; the $\mathrm{CoOl}$ was not intensively involved in further growth of the nuclei, which led to the round shaped particles. When an antimony precursor is injected into a hot solvent, antimony atoms start to coalesce simultaneously with cobalt atoms until a critical concentration is reached at which the metal atoms rapidly form small clusters. These clusters subsequently grow by diffusion, which is believed to proceed under conditions commonly applied during the metal precursor compound injection period. ${ }^{15)}$ A monomer precursor of metal oleates can combine to form small, unstable clusters of increasing free energy. In the case of the hot injection method, the free energy of formation of the $\mathrm{CoSb}_{2}$ particles clusters with very small size distribution and increases with the growth of size until a maximum is reached. Based on these results, further experiments were performed using the hot-injection method.

The structure of the $\mathrm{CoSb}_{2}$ nanoparticles prepared by thermolysis of SbOl-AON3 and CoOl-CSM was analyzed by XRD. Peaks were rather broad, indicating the nanocrystalline character of the as-synthesized $\mathrm{CoSb}_{2}$ nanoparticles. Fig. 4(a) the temperature of $\mathrm{CoOl}-\mathrm{CSM}$ in ODE was increased to $320^{\circ} \mathrm{C}$ and $\mathrm{SbOl}-\mathrm{AON} 3$ was hot-injected into ODE while holding the temperature at $10 \mathrm{~min}$ for the conventional heating method. It was found that the temperature of SbOl-AON3 and CoOl-CSM in ODE increased to $320^{\circ} \mathrm{C}$ temperature was held for $10 \mathrm{~min}$. The major diffraction pattern agrees well with the monoclinic arsenopyrite structure of $\mathrm{CoSb}_{2}$ (space group P21/c). Both hot injection and the conventional method show a single phase without an impurity phase.

Figure 5 shows $\mathrm{SEM}$ images of $\mathrm{CoSb}_{2}$ nanoparticles prepared by thermolysis of SbOl-AON3 and CoOl-CSM at different reaction temperatures. The reaction temperature of $\mathrm{CoOl}-\mathrm{CSM}$ in ODE was increased to a) $250^{\circ} \mathrm{C}$, b) $300^{\circ} \mathrm{C}$ and $320^{\circ} \mathrm{C}$ and SbOl-AON3 monomer precursor was hot-injected into ODE while holding the temperature for $10 \mathrm{~min}$. d) Xray patterns of $\mathrm{CoSb}_{2}$ nanoparticles prepared at $250^{\circ} \mathrm{C}$, $300^{\circ} \mathrm{C}$ and $320^{\circ} \mathrm{C}$. By varying the reaction temperature from $250^{\circ} \mathrm{C}$ to $320^{\circ} \mathrm{C}$, the diameter of the resulting nanocrystal-

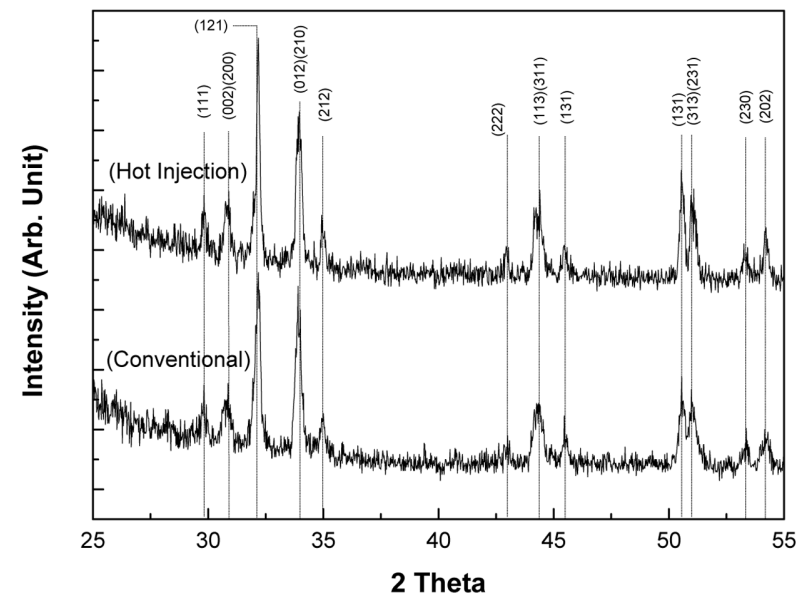

Fig. 4. XRD diffraction patterns of $\mathrm{CoSb}_{2}$ nanoparticles prepared by thermolysis of SbOl-AON3 and CoOl-CSM. The temperature of CoOl-CSM in ODE was increased to $320^{\circ} \mathrm{C}$ and $\mathrm{SbOl}-\mathrm{AON} 3$ was hot-injected into ODE and while holding the temperature for $10 \mathrm{~min}$; in the conventional heating method, the temperature of SbOl-AON3 and CoOl-CSM in ODE were found to increase to $320^{\circ} \mathrm{C}$ with holding of $10 \mathrm{~min}$.
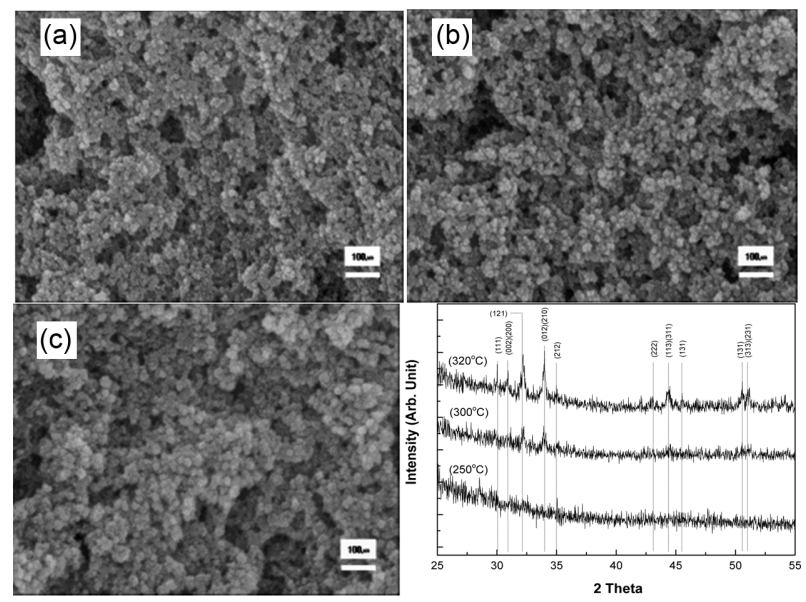

Fig. 5. SEM images of $\mathrm{CoSb}_{2}$ nanoparticles prepared by thermolysis of SbOl-AON3 and CoOl-CSM at different reaction temperatures. The temperature of CoOl-CSM in $\mathrm{ODE}$ was increased to (a) $250^{\circ} \mathrm{C}$, (b) $300^{\circ} \mathrm{C}$ and $320^{\circ} \mathrm{C}$ and SbOl-AON3 was hot-injected into ODE while holding the temperature for $10 \mathrm{~min}$. (d) X-ray patterns of $\mathrm{CoSb}_{2}$ nanoparticles prepared at $250^{\circ} \mathrm{C}$, $300^{\circ} \mathrm{C}$ and $320^{\circ} \mathrm{C}$.

lites can be tuned at the fixed reaction time (10 min). When the reaction temperature was increased, the particle size was found to increase linearly. The crystallinity of the $\mathrm{CoSb}_{2}$ nanoparticles prepared at $250^{\circ} \mathrm{C}$ is amorphous phase without any peaks. $\mathrm{CoSb}_{2}$ structural peaks start to appear at $300^{\circ} \mathrm{C}$ and dominant peaks with high crystallinity are synthesized at $320^{\circ} \mathrm{C}$. When free $\mathrm{OA}$ exists during the reaction, free carboxylic acid will react with the atoms on the surface of the nucleated particles as a reverse reaction, bind to metal atoms and start to leach out as a metal oleate. The 

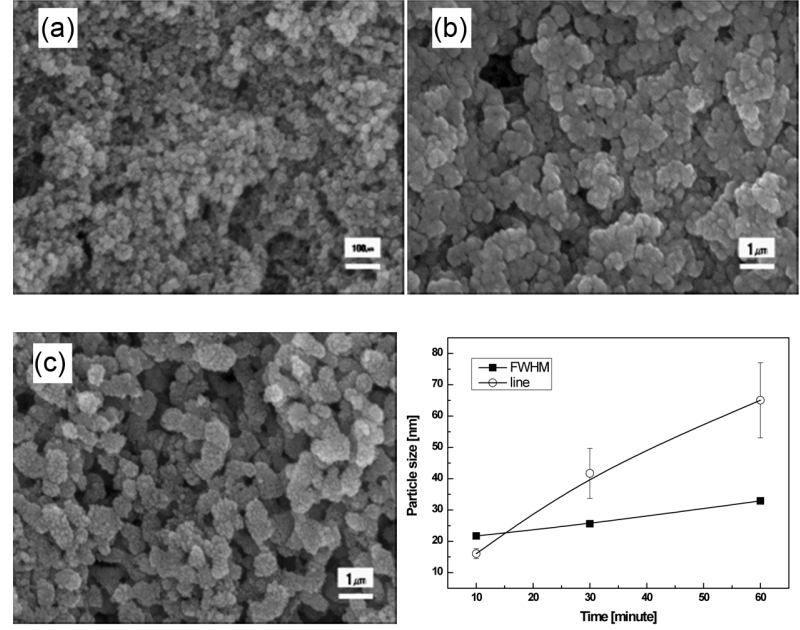

Fig. 6. SEM images of $\mathrm{CoSb}_{2}$ nanoparticles prepared by thermolysis of SbOl-AON3 and CoOl-CSM at different reaction times. The temperature of $\mathrm{CoOl}-\mathrm{CSM}$ in $\mathrm{ODE}$ was increased to a) $320^{\circ} \mathrm{C}$ and $\mathrm{SbOl}-\mathrm{AON} 3$ was hot-injected into ODE while holding the temperature for (a) $10 \mathrm{~min}$, (b) $30 \mathrm{~min}$ and (c) $60 \mathrm{~min}$; (d) the variation of the particle size of Co-Sb nanoparticles depending on reaction time. The particle size was analyzed using the ImageJ program (o) and calculated using the Debye-Scherrer method (๘).

spherical shape of the particles mainly forms because the morphology is thermodynamically more stable than other morphologies in these reaction conditions. However, when the reaction time was prolonged, different morphologies started to appear with irregular crystal growth. This is because the chemical structure of carboxylic acid will decompose under the existence of $\mathrm{CoSb}_{2}$ nanoparticles, which will serve as catalysts at high temperature. To summarize, small amounts of carboxylic acid will enhance the nucleation of nanoparticles. An optimum amount of carboxylic acid will produce monodispersed nanoparticles. However, a prolonged reaction time will cause the decomposition of carboxylic acid, resulting in large size particles with irregular morphologies.

Figure $6 \mathrm{SEM}$ shows images of $\mathrm{CoSb}_{2}$ nanoparticles prepared by thermolysis of SbOl-AON3 and CoOl-CSM at different reaction times. The temperature of the CoOl-CSM in $\mathrm{ODE}$ was increased to a) $320^{\circ} \mathrm{C}$ and SbOl-AON3 was hotinjected into ODE while holding the temperature for a) 10 $\mathrm{min}$, b) $30 \mathrm{~min}$ and c) $60 \mathrm{~min}$; d) variation of the particle size of Co-Sb nanoparticles depending on the reaction time. The particle size was analyzed using the ImageJ program (o) and calculated using the Debye-Scherrer method ( $\mathbf{\square})$. The particle size of $\mathrm{CoSb}_{2}$ nanoparticles by hot-injection of SbOl$\mathrm{AON} 3$ at $320^{\circ} \mathrm{C}$ for $10 \mathrm{~min}$ to $60 \mathrm{~min}$ was found to linearly increase from $15 \mathrm{~nm}$ to $65 \mathrm{~nm}$, as analyzed by the Image $J$ software. The growth rate of $\mathrm{CoSb}_{2}$ nanoparticles was about $1 \mathrm{~nm} / \mathrm{min}$. Also, the crystal size, calculated using the DebyeScherrer equation, was found to linearly increase from 22 $\mathrm{nm}$ to $32 \mathrm{~nm}$ with the growth rate of $0.2 \mathrm{~nm} / \mathrm{min}$. Fig. 7 .

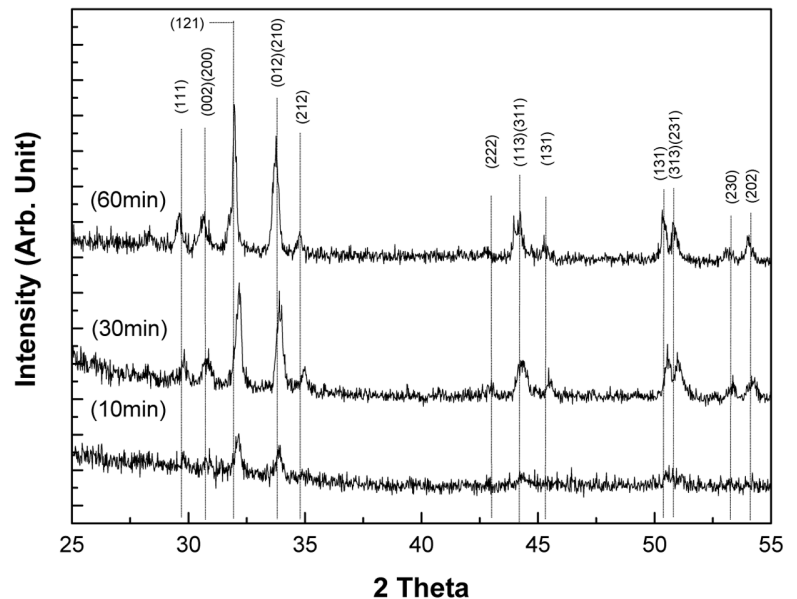

Fig. 7. XRD diffraction patterns of $\mathrm{CoSb}_{2}$ nanoparticles prepared by thermolysis of SbOl-AÔN3 and CoOlCSM at different reaction times. The temperature of CoOl-CSM in ODE was increased to $320^{\circ} \mathrm{C}$ and SbOl-AON3 was hot-injected into ODE while holding the temperature for (a) $10 \mathrm{~min}$, (b) 30 min and (c) $60 \mathrm{~min}$.

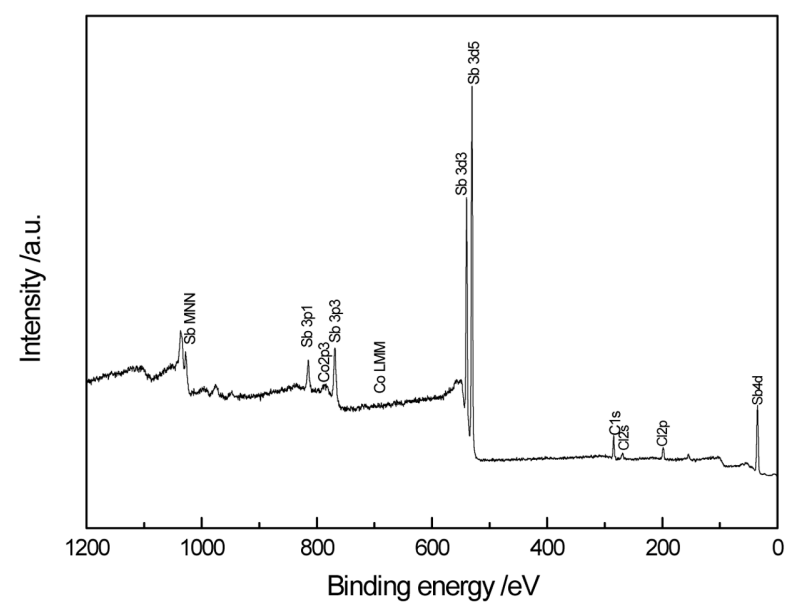

Fig. 8. XPS survey spectrum of $\mathrm{CoSb}_{2}$ nanoparticles prepared by thermolysis of hydrated CoOl-CSM and non-hydrate SbOl-AON3.

XRD diffraction patterns of $\mathrm{CoSb}_{2}$ nanoparticles prepared by thermolysis of SbOl-AON3 and CoOl-CSM at different reaction times. The temperature of $\mathrm{CoOl}-\mathrm{CSM}$ in ODE was found to increase to a) $320^{\circ} \mathrm{C}$ and SbOl-AON3 was hotinjected into ODE while holding the temperature for 10 $\mathrm{min}, 30 \mathrm{~min}$ and $60 \mathrm{~min}$. When the reaction time was prolonged, the crystallinity of the $\mathrm{CoSb}_{2}$ nanoparticles improved.

Figure 8 shows a typical XPS survey spectrum of $\mathrm{Co}-\mathrm{Sb}$ nanoparticles prepared by thermolysis of hydrated $\mathrm{CoOl}$ made by exchanging the cobalt ion with $\mathrm{NaOl}$ and the nonhydrate $\mathrm{SbOl}$ prepared with antimony chloride and OA. Carbon and chloride peaks, belonging to the OA and unreacted metal chloride, respectively, were also defined. The Co2p spectrum shows a complex structure broadened by 
multiple splitting effects, the peaks at 778.4 and $794.2 \mathrm{eV}$ being characteristic of metallic cobalt. Also, the three peaks at 797, 780.6 and $788 \mathrm{eV}$ are characteristic of $\mathrm{CoO}$ and the two peaks at 779.7 and $780 \mathrm{eV}$ correspond to $\mathrm{Co}_{3} \mathrm{O}_{4}$. This means that a passive oxide layer is formed on the surface of the $\mathrm{Co}-\mathrm{Sb}$ nanoparticles during the thermolysis of hydrated $\mathrm{CoOl}$ and/or washing of the Co-Sb nanoparticles with organic solvent and EtOH. Unknown peaks between 779 and $791 \mathrm{eV}$ are co-complexes such as $\mathrm{CoOl}$, with different valences. Concerning the antimony spectrum, the two peaks at 152.6 and $768.5 \mathrm{eV}$ are characteristic of $\mathrm{Sb}$ and the two peaks at 34.5 and $530 \mathrm{eV}$ are allocated to $\mathrm{Sb}_{2} \mathrm{O}_{3}$. The peak at $540.6 \mathrm{eV}$ can be attributed to diantimonytetraoxide $\left(\mathrm{Sb}_{2} \mathrm{O}_{4}\right)$.

\section{Conclusions}

A novel approach for the synthesis of $\mathrm{CoSb}_{2}$ nanoparticles is successively demonstrated by in-situ thermolysis of hydrated $\mathrm{CoOl}$ and non-hydrated SbOl complexes. The synthesis of $\mathrm{CoSb}_{2}$ nanoparticles involves the reaction of metal chloride and carboxylic acid to synthesize the non-hydrated $\mathrm{SbOl}$ complexes; this is followed by the thermolysis of $\mathrm{CoOl}$ and $\mathrm{SbOl}$ in non-coordination solvent. Especially, antimony trichloride is used to directly coordinate the equimolar of metal ions with OA, resulting in non-hydrated SbOl. The hot-injection method was used to overcome the different decomposition temperatures of the non-hydrated $\mathrm{SbOl}$ and hydrate $\mathrm{CoOl}$. The particle sizes of $\mathrm{CoSb}_{2}$ synthesized by thermolysis of metal oleate can be tuned by changing the reaction time and temperature. From the crystallographic analysis of the as-synthesized $\mathrm{CoSb}_{2}$ nanoparticles, the particle has a single phase without any impurity phase. XPS analysis revealed that the surface of the $\mathrm{CoSb}_{2}$ nanoparticles is passivated by a thin oxide layer.

\section{REFERENCES}

1. S. Yehezkel, M. Auinat, N. Sezin, D. Starosvetsky, and Y. Ein-Eli, "Bundled and Densified Carbon Nanotubes (CNT) Fabrics as Flexible Ultra-Light Weight Li-ion Battery Anode Current Collectors," J. Power Sources, 312 109-15 (2016).

2. B. J. Landi, M. J. Ganter, C. D. Cress, R. A. DiLeo, and R. P. Raffaelle, "Carbon Nanotubes for Lithium Ion Batteries," Energy Environ. Sci., 2 [6] 638-54 (2009).

3. X. He, J. Wang, H. Jia, R. Kloepsch, H. Liu, K. Beltrop, and J. Li, "Ionic Liquid-Assisted Solvothermal Synthesis of Hollow Mn2O3 Anode and $\mathrm{LiMn}_{2} \mathrm{O}_{4}$ Cathode Materials for Liion Batteries," J. Power Sources, 293 306-311 (2015).

4. A. S. Arico, P. Bruce, B. Scrosati, J.-M. Tarascon, and W. van Schalkwijk, "Nanostructured Materials for Advanced Energy Conversion and Storage Devices," Nat. Mater., 4 [5] 366-77 (2005).

5. H. Li, L. Shi, Q. Wang, L. Chen, and X. Huang, "Nano-Alloy Anode for Lithium Ion Batteries," Solid State Ionics, 148 [3-4] 247-58 (2002).

6. J. Leibowitz, E. Allcorn, and A. Manthiram, " $\mathrm{FeSn}_{2}-\mathrm{TiC}$
Nanocomposite Alloy Anodes for Lithium Ion Batteries," J. Power Sources, 295 125-30 (2015).

7. B. H. Kim, N. Lee, H. Kim, K. An, Y. I. Park, Y. Choi, K. Shin, Y. Lee, S. G. Kwon, H. B. Na, J.-G. Park, T.-Y. Ahn, Y.-W. Kim, W. K. Moon, S. H. Choi, and T. Hyeon, "LargeScale Synthesis of Uniform and Extremely Small-Sized Iron Oxide Nanoparticles for High-Resolution T1 Magnetic Resonance Imaging Contrast Agents," J. Am. Chem. Soc., 133 [32] 12624-31 (2011).

8. J. Park, K. An, Y. Hwang, J.-G. Park, H.-J. Noh, J.-Y. Kim, J.-H. Park, N.-M. Hwang, and T. Hyeon, "Ultra-LargeScale Syntheses of Monodisperse Nanocrystals," Nat. Mater., 3 [12] 891-95 (2004).

9. A. P. Herrera, L. Polo-Corrales, E. Chavez, J. CabarcasBolivar, O. N. C. Uwakweh, and C. Rinaldi, "Influence of Aging Time of Oleate Precursor on the Magnetic Relaxation of Cobalt Ferrite Nanoparticles Synthesized by the Thermal Decomposition Method," J. Magn. Magn. Mater., 328 41-52 (2013).

10. M. Lin and D. Kim, "In situ Thermolysis of Magnetic Nanoparticles Using Non-Hydrated Iron Oleate Complex," J. Nanopart. Res., 14 [2] 1-13 (2012).

11. A. Repko, D. Nižňanský, and J. Poltierová-Vejpravová, "A Study of Oleic Acid-based Hydrothermal Preparation of CoFe2O4 Nanoparticles," J. Nanopart. Res., 13 [10] 502131 (2011).

12. H. Yang, H. Zhou, C. Zhang, X. Li, H. Hu, H. Wu, and S. Yang, "Water-Soluble Magnetic CoO Nanocrystals Functionalized with Surfactants as T2-Weighed MRI Contrast Agentsin Vitro," Dalton Trans., 40 [14] 3616-21 (2011).

13. G. Clavel, M. G. Willinger, D. Zitoun, and N. Pinna, "Solvent Dependent Shape and Magnetic Properties of Doped ZnO Nanostructures," Adv. Funct. Mater., 17 [16] 3159-69 (2007).

14. H. Shao, H. Lee, Y. Huang, K. InYong, and C. Kim, "Control of Iron Nanoparticles Size and Shape by Thermal Decomposition Method," IEEE Trans. Magn., 41 [10] 338890 (2005).

15. J. Schallibaum, F. H. Dalla Torre, W. R. Caseri, and J. F. Loffler, "Large-Scale Synthesis of Defined Cobalt Nanoparticles and Magnetic Metal-Polymer Composites," Nanoscale, 1 [3] 374-81 (2009).

16. S. H. Sun and C. B. Murray, "Synthesis of Monodisperse Cobalt Nanocrystals and their Assembly into Magnetic Superlattices (invited)," J. Appl. Phys., 85 [8] 4325-30 (1999).

17. J. Xie, G. S. Cao, X. B. Zhao, Y. D. Zhong, and M. J. Zhao "Electrochemical Performances of Nanosized Intermetallic Compound $\mathrm{CoSb}_{2}$ Prepared by the Solvothermal Route," J. Electrochem. Soc., 151 [11] A1905-10 (2004).

18. J. Xie, X. B. Zhao, G. S. Cao, Y. D. Zhong, M. J. Zhao, and J. P. Tu, "Solvothermal Synthesis of Nanosized CoSb2 Alloy Anode for Li-ion Batteries," Electrochim. Acta, 50 [9] 19031907 (2005).

19. P. Amornpitoksuk and S. Suwanboon, "Synthesis, Characterization and Thermal Study of $\mathrm{CoSb}_{2}$ Semiconductor by Mechanical Alloying," J. Alloys Compd., 473 [1-2] 373-75 (2009).

20. B. Rajesh Babu, M. S. R. Prasad, K. V. Ramesh, and Y. 
Purushotham, "Structural and Magnetic Properties of $\mathrm{Ni}_{0.5} \mathrm{Zn}_{0.5} \mathrm{Al}_{\mathrm{x}} \mathrm{Fe}_{2-\mathrm{x}} \mathrm{O}_{4}$ Nano Ferrite System," Mater. Chem. Phys., 148 [3] 585-91 (2014).

21. L. M. Bronstein, X. Huang, J. Retrum, A. Schmucker, M. Pink, B. D. Stein, and B. Dragnea, "Influence of Iron Oleate
Complex Structure on Iron Oxide Nanoparticle Formation," Chem. Mater., 19 [15] 3624-32 (2007).

22. N. Shukla, C. Liu, P. M. Jones, and D. Weller, "FTIR Study of Surfactant Bonding to FePt Nanoparticles," J. Magn. Magn. Mater., 266 [1-2] 178-84 (2003). 